\section{An attempt of biocontrol the tomato-wilt disease caused by Verticillium dahliae using Burkholderia gladioli pv. agaricicola and its bioactive secondary metabolites}

\author{
Hazem S. Elshafie, ${ }^{1}$ Shimaa Sakr, ${ }^{1}$ \\ Sabino A. Bufo, ${ }^{2}$ Ippolito Camele ${ }^{1}$ \\ ${ }^{1}$ School of Agricultural, Forestry, Food \\ and Environmental Sciences (SAFE); \\ ${ }^{2}$ Department of Science, University of \\ Basilicata, Potenza, Italy
}

\begin{abstract}
There is a great interest in discovering new microbial natural biocides such as microbial secondary metabolites to reduce the environmental pollution due to the excessive use of synthetic pesticides. Verticillium wilt, caused by the soil-borne Verticillium dahliae, is a widespread disease in tomato growing in many parts of the world. Burkholderia gladioli pv. agaricicola produces some antimicrobial substances and extracellular hydrolytic enzymes which exhibited promising antimicrobial activity towards several phytopathogens. The aims of the current research are to assess in vitro fungicidal effect of 4 strains of $B$. gladioli pv. agaricicola (ICMP11096, 11097, 12220 and 12322) against $V$. dahliae using culture or cell-free culture filtrate. In situ assay was performed to evaluate the biocontrol effect of the most efficient bacterial strain on wilt disease caused by $V$. dahliae in tomato plants. Results demonstrated that the studied bacterial strain ICMP12322 exerted the highest in vitro antifungal activity against $V$. dahliae which correlated with its ability to produce extracellular hydrolytic enzymes. Furthermore, in situ results showed that the selected bacterial strain significantly minimized the disease incidence.
\end{abstract}

\section{Introduction}

Verticillium dahliae Kleb. (V.dah), the causal agent of verticillium wilt disease, is a soilborne fungus widely spread among a variety of economically important crops. ${ }^{1}$ The most common hosts of V.dah are trees, herbaceous ornamentals and vegetables such as tomato, eggplant and lettuce..$^{2,3}$ Controlling $V . d a h$ is difficult because of the persistence of its microsclerotia in the soil. ${ }^{4}$ V.dah is considered a serious pathogen for the Solanaceae family especially for tomato. ${ }^{5}$
Actually, the isolates of V.dah have been differentiated into two races by virulence assay ${ }^{6}$ which are able to infect different hosts such as tomato and lettuce. . $7,8^{7}$ The above two races of $V$.dah were differentiated also by molecular methods (PCR assay) using a specific primer VdIGSF1 and VdIGSR1.

Different microorganisms exhibited a biocontrol effect against several phytopathogens depending on their antagonistic action through many mechanisms, such as, synthesis of antibiotics, cell-wall degradation enzymes, and production of siderophores. ${ }^{10,11}$ The immune system of the plants can be enhanced locally or systemically by biological agents or abiotic inducers, with or without pathogen infection. ${ }^{12}$

Burkholderia species has been potentially used as biocontrol agents against some phytopathogenic fungi and bacteria in many economically important vegetables such as tomato and pepper and some economically important crops such as cotton, corn, citrus and apple due to its production of antimicrobial substances. ${ }^{13-17}$

The bioactive metabolites produced by B. gladioli Zopf were able to significantly inhibit the conidial germination of Penicillium digitatum, P. expansum and Botrytis cinerea ${ }^{18,19}$ Further studies reported that the biocontrol mechanism of $B$. gladioli in vivo could be explicated by the synergic combination between competition for nutrients and/or space and production of antimicrobial metabolites. ${ }^{16}$

B. gladioli pv. agaricicola Yabuuchi $(B g a)$ is an important pathogen of mushroom because it causes soft rot disease of the fleshy tissues of Agaricus bisporus and Pleurotus eryngii. ${ }^{20,21}$ Several researchers reported the fungicidal effect of $B g a$ against some phytopathogenic fungi such as $B$. cinerea, Aspergillus flavus, A. niger, $P$. digitatum, P. expansum, Sclerotinia sclerotiorum and Phytophthora cactorum..$^{17,20}$

A recent study conducted by Elshafie $e t$ $a l .{ }^{11}$ demonstrated that 4 strains of $B g a$ possess antimicrobial properties and are able to control some phyto and human pathogens such as Bacillus megaterium and Escherichia coli. In addition, Bga produces three important hydrolytic enzymes (chitinase, protease and glucanase) which were suggested to play an essential role in its biological effect. ${ }^{22}$

The objective of this study was: i) to evaluate the in vitro antifungal activity of 4 strains of $B$. gladioli pv. agaricicola ICMP11096, 11097, 12220 and 12322 against $V$. dahliae, ii) to assess the effectiveness of using the most efficient strain in controlling the incidence and severity of verticillium wilt disease on tomato plant.
Correspondence: Ippolito Camele, School of Agricultural, Forestry, Food and Environmental Sciences (SAFE), University of Basilicata, Viale dell'Ateneo Lucano, 10, 85100 , Potenza, Italy.

Fax: +39.0971.205503

E-mail: ippolito.camele@unibas.it

Key words: fungicidal activity, biological control, soil-borne diseases, extracellular hydrolytic enzymes.

Acknowledgments: Thanks for the technical assistance from C.T. Michele Palumbo (SAFE). The authors are also grateful to Giambattista Martino (SAFE) for his assistance.

Contributions: the authors contributed equally.

Conflict of interest: the authors declare no potential conflict of interest.

Received for publication: 13 June 2017.

Accepted for publication: 16 June 2017

This work is licensed under a Creative Commons Attribution-NonCommercial 4.0 International License (CC BY-NC 4.0).

(C) Copyright H.S. Elshafie et al., 2017

Licensee PAGEPress srl, Italy

International Journal of Plant Biology 2017; 8:7263 doi:10.4081/pb.2017.7263

\section{Materials and Methods}

\section{Tested bacterial and fungal strains}

The studied B. gladioli pv. agaricicola was obtained from International Collection of Microorganisms from Plants (ICMP) (Landcare Research, Auckland, New Zealand). The tested strains, ICMP11096, ICMP11097, ICMP12220 and ICMP12322, were maintained as lyophils at $4{ }^{\circ} \mathrm{C}$ and subcultures were obtained on King Agar B medium (KB) for $48 \mathrm{hr}$ at $22 \pm 2^{\circ} \mathrm{C} .{ }^{23}$

The $V$. dahliae strain (no. 465) used in this study, previously identified as Race 2 using molecular methods, ${ }^{24}$ was isolated from symptomatic eggplant (Solanum melongena L.) and maintained in mycotheca at the School of Agricultural, Forestry, Food and Environmental Sciences (University of Basilicata, Potenza, Italy) on potato dextrose agar (PDA) at $8^{\circ} \mathrm{C}$.

\section{In vitro fungicidal activity}

The antifungal activity of the above mentioned 4 strains of B. gladioli pv. agaricicola against $V$. dahliae was carried out by growing the studied bacterial strains on $\mathrm{KB}$ medium and incubated at $25 \pm 2^{\circ} \mathrm{C}$ for $24 \mathrm{~h}$. 
Then $0.5 \mathrm{~cm}^{2}$ agar disc was placed onto the surface of PDA plates following the bacterial disc method as reported by Tomas et $a l .{ }^{25}$ The plates were incubated at $22 \pm 2^{\circ} \mathrm{C}$ for 4-5 days.

The antifungal activity of cell-free filtrate of the above 4 bacterial strains was conducted using the diffusion method. ${ }^{26}$ Erlenmeyer flask containing $150 \mathrm{~mL}$ of liquid minimal mineral medium (MM) were inoculated with $1.5 \mathrm{~mL}$ bacterial suspension containing $10^{8} \mathrm{CFU} / \mathrm{mL}$ and incubated in rotary shaking $(180 \mathrm{rpm})$ at $22 \pm 2{ }^{\circ} \mathrm{C}$ for 7 days. The culture was centrifuged at 20,000 $g$ for $15 \mathrm{~min}$ and filtered using a Millipore membrane $(0.20 \mu \mathrm{m})$. Fifty $\mu \mathrm{L}$ of the previous filtrate was deposited on $14 \mathrm{~mL}$ solid PDA medium inoculated with $0.5 \mathrm{~cm}^{2}$ of fungal disc. After 4-5 days of incubation, the diameter of the fungal mycelium was measured in $\mathrm{mm}$.

\section{In situ experiment}

On the basis of the results obtained from in vitro study, the biocontrol effect of the most efficient strain, was evaluated in situ experiment against $V$. dahliae. Seeds of Solanum lycopersicum L. cv. cerasiforme were surface sterilized by ethanol $(70 \%)$ and then were sowed in cell tray for 15 days. The seedlings were transferred to experimental pots for further treatment as follows.

\section{Bacterial suspension treatments}

A bacterial suspension containing $10^{6}$ CFU/mL of Bga ICMP12322 was prepared in sterilized broth of Minimal Mineral media (MM) from an initial vegetative culture on solid $\mathrm{KB}$ media and was incubated for 5 days at $22 \pm 2{ }^{\circ} \mathrm{C} .{ }^{23}$ The broth culture was then poured into the pots surface (100 $\mathrm{mL} / \mathrm{pot}$ ) of about 15 days after sowing (DAS).

\section{Artificial fungal infection}

A small portion of fungal mycelium with microsclerotia of $V$. dahliae was inoculated in sterilized potato dextrose broth (PDB) and incubated for 7 days at $22 \pm 2^{\circ} \mathrm{C}$. Later on, $50 \mathrm{ml}$ of the prepared broth was inoculated in the soil near roots zone 22 days (DAS)

\section{Assessment of disease incidence}

The plants were monitored daily to observe the eventual appearance of disease symptoms. The disease incidence was assessed using the following scale: $0=$ no symptoms observed; $1=1$ to $20 \%$ of leaf superficial chlorosis; $2=21$ to $50 \%$ of leaf superficial chlorosis; $3=51$ to $80 \%$ of leaf superficial chlorosis; $4=>80 \%$ of leaf superficial chlorosis.
The infection percentage (IP\%) was measured by using equation 1 . The disease index (DI\%) and the control effect (CE\%) were calculated with equations 2 and 3 , respectively using the formulas described by Lee et al. ${ }^{27}$

$\mathrm{IP}=(\mathrm{SL} / \mathrm{TL}) \times 100$

$\mathrm{DI} \%=\left[\sum(\right.$ Scale $\times$ No. of SL $) /$

$(\mathrm{HS} \times \mathrm{TL})] \times 100$

$\mathrm{CE}(\%)=100 \times($ DI.P - DI.B $) /$

DI.P

where: $\mathrm{SL}=$ Symptomatic Leaves; $\mathrm{TL}=$ Total number of Leaves; HS = Highest Scale; DI-P $=$ Disease Index of Pathogen treatment; DI-B = Disease Index of $B g a$ treatment.

\section{Results and Discussion}

\section{In vitro antifungal activity}

Results demonstrated that all studied bacterial strains were able to significantly inhibit the mycelium growth of V.dah in plates (Table 1). Furthermore, the bioactive secondary metabolites produced in cell-free culture filtrate were able to significantly reduce the fungal mycelium growth of

Table 1. In vitro antifungal activity of 4 Bga strains (cultures and cell-free culture filtrates) against V.dab in PDA plates.

\begin{tabular}{lcc} 
Bacterial strains & \multicolumn{2}{c}{$\begin{array}{c}\text { Mean diameter of V.dah mycelium growth }(\mathrm{mm} \pm \mathrm{SD}) \\
\text { Cell-free filtrates }\end{array}$} \\
Control & $83.0 \pm 2.3 \mathrm{a}$ & $85.0 \pm 2.5$ \\
Bga ICMP 11096 & $39.0 \pm 1.6 \mathrm{bc}$ & $33.0 \pm 1.7 \mathrm{~d}$ \\
\hline Bga ICMP 11097 & $42.0 \pm 2.2 \mathrm{~b}$ & $36.0 \pm 1.5 \mathrm{c}$ \\
Bga ICMP 12322 & $36.0 \pm 1.3 \mathrm{c}$ & $32.0 \pm 1.9 \mathrm{~d}$ \\
\hline Bga ICMP 12220 & $40.0 \pm 2.1 \mathrm{~b}$ & $42.0 \pm 2.3 \mathrm{~b}$ \\
\hline
\end{tabular}

Bga = Burkholderia gladioli pv. agaricicola; .dah = Verticillium dahliae . Values followed by different letters in each vertical column are significantly different at $\mathrm{P}<0.05$ according to Tukey $\mathrm{B}$ test. Data are expressed as mean of 3 replicates \pm SDs.

Table 2. Disease index and control effect of plants subjected to different tested treatments.

\begin{tabular}{lcc} 
Treatments & Dl\% & CE\% \\
Control & $1.56 \pm 0.54 \mathrm{c}$ & 100.00 \\
Bga & $1.98 \pm 0.68 \mathrm{c}$ & 100.00 \\
\hline Bga+ V.dah & $4.51 \pm 1.05 \mathrm{~b}$ & 97.41 \\
V.dah & $75.83 \pm 1.39 \mathrm{a}$ & 0.00 \\
\hline
\end{tabular}

Bga = Burkholderia gladioli pv. agaricicola ICMP12322; V.dah = Verticillium dahliae; DI\% = disease index; CE\% = control effect. Values followed by different letters are significantly different at $\mathrm{P}<0.05$ according to Tukey $\mathrm{B}$ test. Data are expressed as mean of 3 replicates \pm SDs.

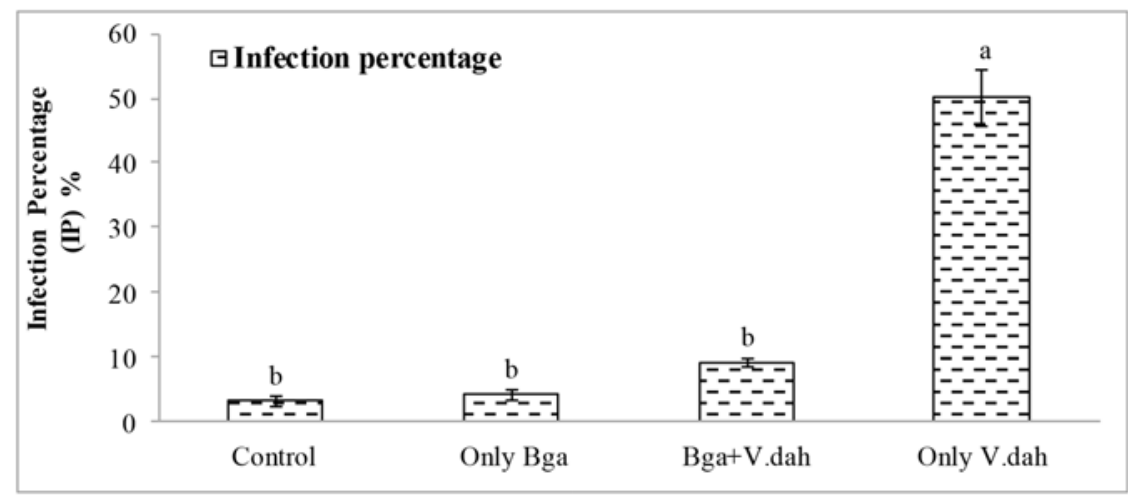

Figure 1. Symptomatic leaves percentage of tomato due to V.dab infection. Bars with different letters indicate mean values significantly different at $\mathrm{P}<0.05$ according to Tukey $\mathrm{B}$ test. Data are expressed as mean of 3 replicates \pm SDs. IP $=[($ Symptomatic leaves $/$ Total number of leaves) $\times 100]$. 
V.dah after 5 days of incubation (Table 1). The antifungal activity derived from both strains ICMP12322 and ICMP11096 were significantly the highest. For the current study, strain ICMP12322 was selected for further in situ experiment.

\section{Reduction of disease symptoms effect}

The artificial infection of V.dah led to the development of leaf yellowing symptoms within 8-12 days after infection (DAI). Full leaf wilting was monitored after 25 DAI, where the infection percentage was evaluated by $50 \%$ for treated plants (positive control) as illustrated in Figure 1. The plants inoculated only with V.dah showed the highest significant disease index estimated by $75.83 \%$ compared to the control plants and to those treated only with $B g a$ ( $1.56 \%$ and $1.98 \%$, respectively).

Whereas, the bacterized plants which were artificially infected by V.dah showed a control effect insignificantly close to the negative control plants as illustrated in Table 2. The application of ICMP12322 $B g a$ strain seemed to trigger an acquired plant systemic resistance (SAR).

Biological control using antagonistic bacteria and fungi would have a great environmental interest and can effectively replace the traditional synthetic agrochemicals to control many phytopathogens. Recently, several Pseudomonas, Burkholderia and Bacillus species have been tested to control some crop diseases and showed promising biological effects compared to agrochemicals. ${ }^{10,16,28}$

Regarding the present study, the appearance of wilted leaves on the V.dah treated tomato plants gave evidence for pathogenic effect of $V$.dah on epigeous and hypogenous portions of the Solanaceae family. Results proved the biocontrolling effect of the studied bacterial strain lead to the high reduction of wilt symptoms on tomato seedlings. The application of bacterial Bga strain could induce a major resistance effect against V.dah.

Similar researchers reported that the use of some PGPB strains such as B. pumilus, B. subtilis and Curtobacterium flaccumfaciens induced significant disease protection against Colletotrichum orbiculare, $P$. syringae pv. lachrymans and Erwinia tracheiphila. ${ }^{29}$ Hossain et al. ${ }^{12}$ reported that a novel endophytic bacterium $B$. oryzicola YC7007 was able to significantly inhibit the bakanae disease of rice caused by Fusarium fujikuroi by inducing systemic resistance and antibiotic production. Similar, Chung et al. ${ }^{28}$ also reported that an endophytic strain of $B$. oryzicola has potentially suppressed the bacterial blight and grain rot of rice caused by Xanthomonas oryzae pv. oryzae and B. glumae, respectively, via resistance induction.

On the other hand, several researchers studied the synergic effectiveness of using more than one biocontrol agent, such as mixtures of fluorescent pseudomonads showed a potential suppressive effect against the incidence of Gaeumannomyces graminis var. tritici. ${ }^{30}$ Although the potential effect of the current studied bacterial strain to control V.dah in tomato plant is adequate in conventional agriculture, however, the combinations between different biological agents and chemical controls may achieve the effective disease suppression on the short term.

\section{Conclusions}

The disease index calculated for bacterized tomato plants challenged with V.dah was significantly reduced compared to the positive control indicating that tomato plants treated with Bga ICMP12322 exhibited a significant disease resistance. In conclusion, the results presented here indicate that the application of Bga strain 12322 can enhance disease protection and improve the consistency of biological control against wilt disease caused by V.dah. Further studies are still needed to assess the effectiveness of the studied strains as well as other $B g a$ strains to be used in open field experiments and to study the biocontrolling effect of the combination between more than one biological and/or agrochemical agent.

\section{References}

1. Pegg GF, Brady BL. Verticillium wilts. Oxford, UK: CABI Publishing; 2002;539 pp.

2. Hagiwara H. Differentiation of the pathogenicity of Verticillium dahliae in Japan. Plant Protect 1990;44:299-303.

3. Vallad GE, Subbarao KV. Colonization of resistant and susceptible lettuce cultivars by a green fluorescent proteintagged isolate of Verticillium dahliae. Phytopathol 2008;98:871-85.

4. Talboys PW. Chemical control of Verticillium wilts. Phytopathol Mediterr 1984;23:163-75.

5. Jabnoun-Khiareddine H, DaamiRemadi M, Hibar $K$, et al. Pathogenicity of Tunisian isolates of three Verticillium species on tomato and eggplant. Plant Pathol J 2006;5:199207.

6. Vallad GE, Qin QM, Grube RC, et al.
Characterization of race-specific interactions among isolates of Verticillium dahliae pathogenic on lettuce. Phytopathol 2006;96:1380-7.

7. Fradin EF, Thomma BP. Physiology and molecular aspects of Verticillium wilt diseases caused by V. dahliae and V. alboatrum. Mol Plant Pathol 2006;7:7186.

8. Klosterman SJ, Atallah ZK, Vallad GE, Subbarao KV. 2009. Diversity, pathogenicity, and management of Verticillium species. Annu Rev Phytopathol 2009;47:39-62.

9. Maruthachalam K, Atallah Z, Vallad G, et al. Molecular variation among isolates of Verticillium dahliae and polymerase chain reaction-based differentiation of races. Phytopathol 2010;100: 1222-30.

10. Lucy M, Reed E, Glick BR. Application of free living plant-promoting rhizobacteria. Ant Van Lee 2004;86:1-25.

11. Elshafie SH, Racioppi R, Bufo SA, Camele I. In vitro study of biological activity of four strains of Burkholderia gladioli pv. agaricicola and identification of their bioactive metabolites using GC-MS. Saudi J Biol Sci 2017;24:295301.

12. Hossain MT, Khan A, Chung EJ, et al. Biological control of rice bakanae by an endophytic bacillus oryzicola YC7007. Plant Pathol J 2016;32:228-41

13. Cain CC, Henry AT, Waldo RH, et al. Identification and characteristics of a novel Burkholderia strain with broadspectrum antimicrobial activity. Appl Environ Microbiol 2000;66:4139-41.

14. Perin L, Martinez-aguilar L, ParedesValdez G, et al. Burkholderia silvatlantica sp. nov. a diazotrophic bacterium associated with sugar cane and maize. Int J Syst Evol Micriobiol 2006;56:1931-7.

15. Scuderi G, Bonaccorsi A, Panebianco S, et al. Some strains of Burkholderia gladioli are potential candidates for postharvest biocontrol of fungal rots in citrus and apple fruits. J Plant Pathol 2009;91:207-13.

16. Elshafie HS, Camele I, Ventrella E, et al. Use of plant growth promoting bacteria (PGPB) for promoting tomato growth and its evaluation as biological control agent. Int $\mathrm{J}$ Microbiol Res 2013;5:452-7.

17. Elshafie HS, Camele I, Racioppi R, et al. In vitro antifungal activity of Burkholderia gladioli pv. agaricicola against some phytopathogenic fungi. Int J Mol Sci 2012;13:16291-302.

18. Walker R, Innes CMJ, Allan EJ. The potential biocontrol agent Pseudomonas 
antimicrobica inhibits germination of conidia and outgrowth of Botrytis cinerea. Lett Appl Microbiol 2001;32:346-8.

19. Altindag M, Sahin M, Esitken A, et al. Biological control of brown rot (Monilinia laxa Er.) on apricot (Prunus armeniaca L. cv. Hacihaliloglu) by Bacillus, Burkholderia, and Pseudomonas application under in vitro and in vivo conditions. Biol Control 2006;38:369-72.

20. Elshafie HS, Lamorte D, Lelario F, et al. Characterization of Bioactive Secondary Metabolites by Burkholderia gladioli pv. agaricicola. In: book of abstracts of the Fourth international conference on natural toxins. Conference session c - microbial toxins and food poisoning. Ismailia- Egypt. December 20-22, 2010;99-100.

21. Prashanth SN, Bianco G, Cataldi TR, Iacobellis NS. Acyl homoserine lactone production by bacteria associated with cultivated Mushrooms. J Agric Food Chem 2011;59:11461-72.

22. Ordentlich A, Elad Y, Chet I. The role of chitinase of Serratia marcescens in biocontrol of Sclerotium rolfsii. Phytopathol 1988;78:84-92.

23. King EO, Ward MK, Raney DE. Two simple media for demonstration of pyocyanin and fluorescin. J Lab Clin Med 1954;44:301-7.

24. Short DPG, Gurung S, Maruthachalam $\mathrm{K}$, et al. Verticillium dahliae race 2-specific PCR reveals a high frequency of race 2 strains in commercial spinach seed lots and delineates race structure. Phtopathol 2014;104:779-85.

25. Tomas MJE, Simone PMD, Congergado F, Suarez FG. Methods to assess antagonism of soil microorganisms towards fungal spore germination. Soil Biol Biochem 1980;12:197-8.

26. Mehmood Z, Ahmed I, Mohammad F, Ahmed S. Indian medicinal plants: a potential source of anticandidial drug.
Pharm Biol 1999;37:237-42.

27. Lee KJ, Kamala-Kannan S, Sub HS, et al. Biological control of Phytophthora blight in red pepper (Capsicum annuum L.) using Bacillus subtilis. World J Microbiol Biotecnol 2008;24:1139-45.

28. Chung EJ, Hossain MT, Khan A, et al. Bacillus oryzicola sp. nov., an endophytic bacterium isolated from the root of rice with antimicrobial, plant-growth promoting and systemic resistance inducing activities in rice. Plant Pathol $\mathrm{J}$ 2015;31:152-64.

29. Raupach GS, Kloepper JW. Mixtures of plant growth-promoting rhizobacteria enhance biological control of multiple cucumber pathogens. Phytopathol 1998;88:1158-64.

30. Pierson EA, Weller DM. Use of mixtures of fluorescent pseudomonads to suppress take-all and improve the growth of wheat. Phytopathol 1994;84:940-7. 